\title{
The current status of hand washing and glove use among care staff in Japan: its association with the education, knowledge, and attitudes of staff, and infection control by facilities
}

\author{
Ikuko Takahashi · Yoneatsu Osaki • \\ Mikizo Okamoto · Aya Tahara · Takuji Kishimoto
}

Received: 17 December 2008/Accepted: 31 July 2009/Published online: 25 August 2009

(C) The Japanese Society for Hygiene 2009

\begin{abstract}
Objective Hand hygiene is a basic measure to prevent infections. The purpose of this study was to obtain suggestions for the improvement of hand hygiene by evaluating the education, knowledge, and attitudes of care staff at facilities for the elderly in regard to hand washing and glove use, as well as infection control policies by those facilities. Methods Among a total of 147 special nursing homes and health service facilities for the elderly in Yamaguchi Prefecture, Japan, questionnaires were sent from October to November 2007 to 56 facilities which had agreed to participate in this survey. Two types of questionnaire, one for the facility manager and the other for care staff, were sent to each facility.

Results The questionnaire was responded to by 42 managers (response rate 28.6\%) and 1,323 staff members (response rate $26.3 \%$ ). The rate of compliance with hand hygiene among them was $34.0 \%$. Personal factors promoting hand hygiene were education and attitudes, while facility-related factor was the implementation of handwashing evaluation.

Conclusion Since the hand hygiene compliance rate is low among care staff at facilities for the elderly, it is necessary to take measures to improve hand hygiene.
\end{abstract}

I. Takahashi $(\bowtie)$

Faculty of Health Sciences, Yamaguchi University Graduate

School of Medicine, 1-1-1 Minamikogushi,

Ube, Yamaguchi 755-8505, Japan

e-mail: t-ikuko@yamaguchi-u.ac.jp

Y. Osaki · M. Okamoto · A. Tahara - T. Kishimoto

Division of Environmental and Preventive Medicine,

Department of Social Medicine, Faculty of Medicine,

Tottori University, Nishi-machi 86,

Yonago, Tottori 683-8503, Japan
Educational programs for hand hygiene should be developed in view of the conditions of individual facilities.

Keywords Hand washing - Glove - Hand hygiene · Facilities for the elderly - Care staff

\section{Introduction}

Hand hygiene is emphasized as a basic measure to prevent infections. However, the rate of compliance with hand hygiene in medical practitioners is low, and the US Centers for Disease Control and Prevention (CDC) published a guideline for hand hygiene in healthcare settings in an effort to promote it [1]. Hand hygiene means either washing the hands with soap and water or hand antisepsis with an alcohol-based hand-rub [2].

Research on hand hygiene at facilities has mainly targeted physicians and nurses working for hospitals. In Japan, Osuka [3] investigated the rate of practicing hand washing and factors affecting hand hygiene behavior among 93 nurses at two hospitals, and reported that the rate was $50.9 \%$ on average, and factors such as workload, education, and experience affected hand hygiene behavior.

Infection control is important at special nursing homes and health service facilities for the elderly as well as at hospitals. These facilities for the elderly, however, less frequently involve invasive procedures [4], and therefore they are expected to depend more on hand hygiene for the prevention of infections. Challenges to infection control at facilities for the elderly have been reported, including: (1) there are many elderly people who cannot voluntarily take preventive actions such as hand washing due to paralysis or dementia, and this impairs the effectiveness of infection control; (2) elderly residents are often less resistant due to 
their chronic diseases [5]; (3) there are few medical practitioners at facilities for the elderly, as special nursing homes do not have a system of resident physicians/nurses [6]. Thus, care workers and nurses (care staff) who take care of residents were expected to play an important role in preventing infections at facilities for the elderly.

When an outbreak of norovirus infection occurred at facilities for the elderly over the period from December 2004 to January 2005, with 7 deaths of residents at a special nursing home, the Ministry of Health, Labor, and Welfare issued a notification requiring those facilities to strengthen their infection control measures [7]. The number of cases infected by norovirus at facilities for the elderly is rising annually; it increased by more than 2.5 times during the period from September 2006 to August 2007 [8]. Infection with norovirus is the most common at facilities for the elderly, and the route of infection is human-tohuman infection [9]. Since the possibility of norovirus being transmitted to multiple patients by a single care worker who missed a single occasion of hand hygiene has been demonstrated [10], it is important for, and a challenge to, facilities for the elderly to encourage care staff to comply with hand hygiene measures.

Regardless of the importance of promoting hand hygiene among care staff at facilities for the elderly, studies targeting individual facilities or surveying the compliance of care staff with hand hygiene on the occasion of their attending a training session have only been conducted in Japan; no study has investigated the current status of hand hygiene, and factors associated with it, among care staff. Given the association of various factors with the practice of hand hygiene [11], it is necessary to clarify both personal and facility-related factors to improve the compliance of care staff.

Focusing on the practice of hand washing and glove use as preventive measures against infection, and targeting care staff at facilities for the elderly, this study evaluated their education, knowledge, and attitudes in regard to hand washing and glove use, as well as infection control by those facilities, to clarify the relationships between these conditions and compliance with hand hygiene.

\section{Materials and methods}

\section{Subjects}

The subjects were the managers and care staff of special nursing homes and health service facilities for the elderly in Yamaguchi Prefecture, Japan.

The target institutions were 147 facilities for the elderly (87 special nursing homes and 60 health service facility) in Yamaguchi Prefecture, Japan, listed as of December 14,
2006, on the Welfare and Medical Service Network System (WAMNET). Each of the 147 facilities was requested in writing to participate in this study, and a questionnaire was sent to 56 facilities ( 31 special nursing homes and 25 health service facilities) which had agreed to cooperate with us. The questionnaire survey was conducted from October 22, 2007 to November 10, 2007.

The questionnaire for managers was collected from 42 facilities. The response rate was $28.6 \%$, and 41 facilities $(27.9 \%)$ were used for analysis. On the other hand, the questionnaire for care staff was answered by $1,323(26.3 \%)$ of a total of 5,026 staff members; $1,282(25.5 \%)$ who answered all of the 9 questions about hand washing and glove use were subjected to analysis.

To evaluate any bias in the characteristics of these facilities, 41 responding and 91 nonresponding facilities, excluding 15 whose attitudes to the survey were unclear, were tested for location, type, capacity, and number of care staff, but no significant differences were found.

\section{Data collection}

A questionnaire was developed in consultation with previous studies [3,12, 13], the CDC guideline for hand hygiene in healthcare settings [1], and an infection control manual by the Ministry of Health, Labor, and Welfare [14] for the elderly in a facility.

A copy of the questionnaire for the facility manager and a necessary number of copies for care staff were sent in an envelope to each facility.

The completed questionnaire for care staff was put in an envelope by each staff member, collected together with that for the facility manager, and returned by the person responsible at each facility.

\section{Survey items}

\section{Questionnaire for the facility manager}

Items of the questionnaire for the facility manager included basic characteristics (facility type, capacity, number of staff, numbers of new/retired employees), resident information (number of residents by care level), establishment of an infection control committee, presence of an infection control manual, provision of infection and hand-washing training, implementation of hand-washing evaluation, guidance for hand washing and glove use, vaccination (influenza, Streptococcus pneumoniae, hepatitis B), stocks of disposable gloves, gowns, masks, and N95 masks, availability of private rooms upon the onset of infection, availability of a sink in the residents' rooms, installation of alcohol-based hand-rubs, and carrying of alcohol-based hand-rub in the pocket. 


\section{Questionnaire for care staff}

Items on the questionnaire for care staff included basic characteristics (age, gender, job type, years of experience, years of continuous employment, employment status), education (receipt of pre- and post-employment education on infection and hand washing), practice of hand washing and glove use, knowledge of infection routes (itch, methicillin-resistant Staphylococcus aureus [MRSA], influenza virus, tubercle bacillus [TB], hepatitis $\mathrm{B}$ and $\mathrm{C}$ viruses, human immunodeficiency virus [HIV], norovirus), knowledge of hand washing (hand-washing methods for visibly unsoiled and soiled hands), and attitudes (thinking that you will take standard precautions, that hand washing is effective, that infection can be prevented by knowledge, that infection can be prevented by proper behavior, that you have knowledge of infection, that you can take appropriate actions in poor health, and that you are busy at work).

\section{Statistical analysis}

The statistical software package SPSS version 15.0 for Windows was used for statistical analysis.

Hand washing and glove use were designated as dependent variables, and those who answered yes to all of the 9 questions about the practice of "hand washing required by the CDC guideline for hand hygiene in healthcare settings [1]," "hand washing during daily work," and "glove use required by standard precautions $[15,16]$ " were regarded as the hand-hygiene compliant group, and those who answered no to any of the 9 questions were regarded as the hand hygiene noncompliant group. The questions were about: (1) hand washing before direct contact with residents, (2) hand washing after direct contact with residents, (3) hand washing when moving from a contaminated body site to a clean one during resident care, (4) hand washing after removing gloves, (5) hand washing before eating and after using the restroom, (6) hand washing during busy work, (7) use of a new pair of gloves for each care episode, (8) glove use in the presence of possible infection, and (9) glove replacement when moving from a contaminated body site to a clean one during resident care.

Although glove use itself cannot guarantee hand hygiene [1], this study considered it within the scope of hand hygiene as the standard precautions require glove use as a measure to prevent infection via the hands.

\section{Analysis of personal factors and compliance with hand hygiene}

Correlations between the levels of compliance with hand hygiene and the variables of care staff were examined by the chi-square test or $t$ test.
To clarify personal factors contributing to compliance with hand hygiene, multiple logistic regression analysis was performed with hand hygiene compliance levels used as dependent variables, and basic characteristics, education, knowledge, and attitudes as explanatory variables.

The variables entered were "years of experience," "job type (nurse or other)," "education," "knowledge of handwashing methods for visibly soiled or unsoiled hands," "knowledge of infection routes of infection with scabies, MRSA, influenza, TB, hepatitis B/C, HIV, or norovirus," "I think I will take standard precautions," "I think hand washing is effective in preventing infection," "I think infection can be prevented by knowledge," "I think infection can be prevented by proper behavior," "I think I have knowledge of infection," "I think I can take appropriate actions in poor health," and "I think I am busy at work."

For the variable "education," those who answered "received adequate education" or "received education" on both infection and hand washing before employment, and "received training" on both infection and hand washing after employment were regarded as adequate, and others were regarded as inadequate.

\section{Analysis of facility-related factors and compliance rate with hand hygiene}

To clarify the relationships between those facilities conditions and compliance rate with hand hygiene, multiple regression analysis was performed compliance rate with hand hygiene used as dependent variables, and basic characteristics and infection control by the facility and its environment as explanatory variables.

The variables entered were "facility type," "number of residents per staff member," "infection training," "implementation of hand-washing evaluation," "handwashing environment in the residents' room," "carrying an alcohol-based hand-rub in the pocket," and "guidance for hand-washing and glove use."

The variable "hand-washing environment in the residents' room," was categorized into three: both a sink and alcohol-based hand-rub available was scored as 2 point, either one available was scored as 1 point, or both unavailable was scored as 0 point.

For the variable "guidance for hand-washing and glove use," the correct answer to 8 questions for care staff with hand-washing and glove use, except the question about hand washing during busy work, guidance by explain was scored as 2 point, only paper was scored as 1 point, no guidance was scored as 0 point, and then these values were summed. 
Ethical considerations

Explanation to the subjects was made by the responsible person at each facility using briefing material that described the purpose of the survey, how to complete the questionnaire, protection of privacy, the completely voluntary nature of participating in the study, and consideration for the subjects not to be disadvantaged.

This study was conducted with the approval of the Medical Research Ethics Committee of the Faculty of Health Sciences, Yamaguchi University Graduate School of Medicine.

\section{Results}

The overall condition of the facilities

By facility type, $52.4 \%$ were special nursing homes and $47.6 \%$ were health service facilities. Capacity was $78.4 \pm 20.9$ (mean \pm standard deviation, SD) and number of staff was $39.8 \pm 14.8$ (mean $\pm \mathrm{SD}$ ).

Regarding the facility environment, "availability of a sink in the residents' room" (56.1\%), "installation of alcohol-based hand-rubs" (43.9\%), and "carrying an alcohol-based hand-rub in the pocket" $(24.4 \%)$ were confirmed (Table 1).

Personal factors and compliance with hand hygiene

The subjects included more women $(79.1 \%)$ than men (20.9\%); mean age was 37.5 years. Regarding job type, "certified care worker" was the most common (51.1\%), followed by "care worker (helper)" (20.7\%) and "nurse" $(17.5 \%)$. Compliance with hand hygiene was confirmed in $436(34.0 \%)$ of the 1,282 staff members, being $30.5 \%$ in certified care workers, $33.7 \%$ in care workers (helpers), and
$41.5 \%$ in nurses. No item of the basic characteristics showed significant difference between the hand-hygienecompliant and noncompliant groups (Table 2).

Regarding pre- and post-employment education, about $50 \%$ of care staff stated they had "received adequate education" or "received education" on both infection and hand washing before employment, and some 60-70\% of them had received such education after employment. For all items, the compliant group had more educated staff members than the noncompliant group, showing a significant difference except for the item "previous receipt" of "post-employment education on infection" (Table 3).

Those who chose alcohol-based hand-rubs as a handwashing method for visibly unsoiled hands accounted for $31.2 \%$. Concerning their knowledge of infection routes, more than $90 \%$ answered correctly for scabies, influenza virus, and norovirus, whereas the correct answer for tuberculosis (TB) was given by some $80 \%$; the lowest rate was $49.5 \%$, for methicillin resistant Staphylococcus aureus (MRSA). For each of influenza virus, TB, hepatitis B/C viruses, and HIV, a significant difference was observed, with more correct answers in the noncompliant group (Table 4).

Regarding attitudes toward hand hygiene, those who answered yes to each of the questions regarding thinking "that infection can be prevented by knowledge" and "that infection can be prevented by proper behavior" were significantly more common in the compliant group. Those who thought they "had knowledge of infection," and/or "could take appropriate actions such as having a rest and seeing a doctor in poor health" accounted for about $50 \%$ of all; more precisely, those with the positive attitude comprised $58.2 \%$ and $41.5 \%$ of the compliant and noncompliant groups, respectively, and those with the negative attitude comprised $65.3 \%$ and $46.5 \%$, respectively (Table 5).
Table 1 Facility conditions $(n=41)$

\begin{tabular}{llll}
\hline Item & Category & & Values \\
\hline Facility type & Special nursing home & $n(\%)$ & $22(53.7)$ \\
& Health service facility & & $19(46.3)$ \\
Capacity & Number & Mean \pm SD & $78.4 \pm 20.92$ \\
Number of staff & Number & Mean \pm SD & $39.8 \pm 14.78$ \\
Number of residents per staff member & Number & Mean \pm SD & $1.9 \pm 0.37$ \\
Compliance rate with hand hygiene & Proportion & Mean \pm SD & $34.7 \pm 16.41$ \\
Infection training & Yes & $n(\%)$ & $33(80.5)$ \\
Implementation of hand-washing evaluation & Yes & $n(\%)$ & $23(56.1)$ \\
Availability of a sink in the residents room & Yes & $n(\%)$ & $25(61.0)$ \\
Installation of alcohol-based hand-rubs & Yes & $n(\%)$ & $18(43.9)$ \\
Carrying an alcohol-based hand-rub in the pocket & Yes & $n(\%)$ & $10(24.4)$ \\
Guidance for hand washing and glove use & Score & Mean \pm SD & $10.0 \pm 3.40$ \\
\hline
\end{tabular}


Table 2 Basic characteristics and compliance with hand hygiene $(n=1,282)$

\begin{tabular}{|c|c|c|c|c|c|c|}
\hline Item & Category & & Total & $\begin{array}{l}\text { Compliant } \\
n=436\end{array}$ & $\begin{array}{l}\text { Noncompliant } \\
n=846\end{array}$ & $P$ value \\
\hline \multirow[t]{2}{*}{ Gender } & Male & $n(\%)$ & 268 (20.9) & 99 (22.8) & $169(20.0)$ & 0.246 \\
\hline & Female & & $1,013(79.1)$ & $336(77.2)$ & $677(80.0)$ & \\
\hline Age & Year & Mean \pm SD & $37.5 \pm 12.21$ & $37.1 \pm 12.26$ & $37.5 \pm 12.09$ & 0.642 \\
\hline Years of experience & Year & Mean \pm SD & $8.8 \pm 8.21$ & $9.3 \pm 9.04$ & $8.5 \pm 7.64$ & 0.109 \\
\hline Years of continuous employment & Year & Mean \pm SD & $5.3 \pm 5.16$ & $5.4 \pm 5.41$ & $5.3 \pm 5.02$ & 0.759 \\
\hline \multirow[t]{5}{*}{ Job type } & Nurse & $n(\%)$ & $224(17.5)$ & $91(21.0)$ & $133(15.8)$ & 0.112 \\
\hline & Certified care worker & & $652(51.1)$ & $205(47.3)$ & $447(53.0)$ & \\
\hline & Care worker (helper) & & $264(20.7)$ & $94(21.7)$ & $170(20.1)$ & \\
\hline & Others & & $27(2.1)$ & $10(2.3)$ & $17(2.0)$ & \\
\hline & Unqualified & & $110(8.6)$ & $33(7.6)$ & $77(9.1)$ & \\
\hline \multirow[t]{2}{*}{ Facility type } & Special nursing home & $n(\%)$ & $715(56.7)$ & $243(56.3)$ & $472(56.9)$ & 0.815 \\
\hline & Health service facility & & $546(43.3)$ & $189(43.8)$ & $357(43.1)$ & \\
\hline \multirow[t]{2}{*}{ Employment status } & Full-time & $n(\%)$ & $1,132(89.3)$ & $388(90.0)$ & $744(89.0)$ & 0.574 \\
\hline & Part-time & & $135(10.7)$ & $43(10.0)$ & $92(11.0)$ & \\
\hline
\end{tabular}

Chi-square test, $t$ test

Table 3 Education and compliance with hand hygiene $(n=1,282)$

\begin{tabular}{|c|c|c|c|c|c|c|}
\hline Item & Category & & Total & $\begin{array}{l}\text { Compliant } \\
n=436\end{array}$ & $\begin{array}{l}\text { Noncompliant } \\
n=846\end{array}$ & $P$ value \\
\hline \multirow{5}{*}{$\begin{array}{l}\text { Pre-employment education on } \\
\text { infection }\end{array}$} & Received adequate education & $n(\%)$ & $114(9.0)$ & $61(14.0)$ & $53(6.4)$ & 0.000 \\
\hline & Received education & & $505(39.8)$ & $183(42.0)$ & $322(38.6)$ & \\
\hline & Received education, but not adequate & & $391(30.8)$ & $123(28.2)$ & $268(32.1)$ & \\
\hline & Yet to receive education & & $193(15.2)$ & $48(11.0)$ & $145(17.4)$ & \\
\hline & Unsure & & $67(5.3)$ & $21(4.8)$ & $46(5.5)$ & \\
\hline \multirow{5}{*}{$\begin{array}{l}\text { Pre-employment education on } \\
\text { hand washing }\end{array}$} & Received adequate education & $n(\%)$ & $153(12.1)$ & $78(17.9)$ & $75(9.0)$ & 0.000 \\
\hline & Received education & & $548(43.2)$ & $196(45.0)$ & $352(42.2)$ & \\
\hline & Received education, but not adequate & & $331(26.1)$ & $89(20.5)$ & $242(29.0)$ & \\
\hline & Yet to receive education & & $162(12.8)$ & $50(11.0)$ & $112(13.4)$ & \\
\hline & Unsure & & $75(5.9)$ & $22(5.1)$ & $53(6.4)$ & \\
\hline \multirow{4}{*}{$\begin{array}{l}\text { Post-employment education on } \\
\text { infection }\end{array}$} & Received training & $n(\%)$ & $941(74.5)$ & 333 (77.6) & $608(72.9)$ & 0.068 \\
\hline & Yet to receive training & & $322(25.5)$ & $96(22.4)$ & $226(27.1)$ & \\
\hline & Received training within the past year & $n(\%)$ & $745(60.1)$ & $274(65.4)$ & $471(57.4)$ & 0.007 \\
\hline & Received no training within the past year & & $494(39.9)$ & 145 (34.6) & $349(42.6)$ & \\
\hline \multirow{4}{*}{$\begin{array}{l}\text { Post-employment education on } \\
\text { hand washing }\end{array}$} & Received training & $n(\%)$ & $907(72.1)$ & $337(78.9)$ & $570(68.6)$ & 0.000 \\
\hline & Yet to receive training & & $351(27.9)$ & $90(21.1)$ & $261(31.4)$ & \\
\hline & Received training within the past year & $n(\%)$ & $712(57.8)$ & $267(64.2)$ & $445(54.5)$ & 0.001 \\
\hline & Received no training within the past year & & $520(42.2)$ & $149(35.8)$ & $371(45.5)$ & \\
\hline
\end{tabular}

Chi-square test

Personal factors contributing to compliance with hand hygiene

Multiple logistic regression analysis was performed using hand hygiene compliance levels as dependent variables, and personal factors such as basic characteristics, education, knowledge, and attitudes as explanatory variables.

The results showed that the item "I think infection can be prevented by knowledge" was the strongest factor promoting compliance with hand hygiene (odds ratio, OR 
Table 4 Knowledge and compliance with hand hygiene $(n=1,282)$

\begin{tabular}{|c|c|c|c|c|c|c|c|}
\hline Item & Category & & & Total & $\begin{array}{l}\text { Compliant } \\
n=436\end{array}$ & $\begin{array}{l}\text { Noncompliant } \\
n=846\end{array}$ & $P$ value \\
\hline \multirow[t]{4}{*}{ Hand-washing methods } & \multicolumn{2}{|c|}{ Soap for visibly soiled hands } & $n(\%)$ & $1,114(87.9)$ & 364 (84.7) & $750(89.5)$ & 0.012 \\
\hline & \multicolumn{2}{|c|}{ Methods other than soap for visibly soiled hands } & & $154(12.1)$ & $66(15.3)$ & $88(10.5)$ & \\
\hline & \multicolumn{2}{|c|}{ A hand-rub for visibly unsoiled hands } & $n(\%)$ & $395(31.2)$ & $153(35.6)$ & $242(28.9)$ & 0.015 \\
\hline & \multicolumn{2}{|c|}{ Methods other than a hand-rub for visibly unsoiled hands } & & $872(68.8)$ & $277(64.4)$ & $595(71.1)$ & \\
\hline \multirow[t]{14}{*}{ Infection routes } & \multirow[t]{2}{*}{ Scabies } & Contact transmission & $n(\%)$ & $1,148(91.4)$ & $388(90.9)$ & $760(91.7)$ & 0.628 \\
\hline & & Routes other than contact & & 108 (8.6) & $39(9.1)$ & $69(8.3)$ & \\
\hline & \multirow[t]{2}{*}{ MRSA } & Contact transmission & $n(\%)$ & $614(49.5)$ & $198(47.0)$ & $416(50.8)$ & 0.209 \\
\hline & & Routes other than contact & & $626(50.5)$ & $223(53.0)$ & $403(49.2)$ & \\
\hline & \multirow[t]{2}{*}{ Influenza } & Droplet transmission & $n(\%)$ & $1,204(95.0)$ & $398(92.6)$ & $806(96.3)$ & 0.004 \\
\hline & & Routes other than droplet & & $63(5.0)$ & $32(7.4)$ & $31(3.7)$ & \\
\hline & \multirow[t]{2}{*}{ TB } & Airborne transmission & $n(\%)$ & $982(78.8)$ & $319(75.6)$ & $663(80.5)$ & 0.047 \\
\hline & & Routes other than airborne & & $264(21.2)$ & $103(24.4)$ & $161(19.5)$ & \\
\hline & \multirow[t]{2}{*}{ Hepatitis B/C } & Blood transmission & $n(\%)$ & $1,084(86.3)$ & $356(83.2)$ & $728(87.9)$ & 0.020 \\
\hline & & Routes other than blood & & $172(13.7)$ & $72(16.8)$ & $100(12.1)$ & \\
\hline & \multirow[t]{2}{*}{ HIV } & Blood transmission & $n(\%)$ & $1,111(88.9)$ & $366(86.3)$ & $745(90.2)$ & 0.039 \\
\hline & & Routes other than blood & & $139(11.1)$ & $58(13.7)$ & $81(9.8)$ & \\
\hline & \multirow[t]{2}{*}{ Norovirus } & Contact/droplet transmission & $n(\%)$ & $1,238(98.7)$ & $421(99.1)$ & 817 (98.6) & 0.450 \\
\hline & & Routes other than contact/droplet & & $16(1.3)$ & $4(0.9)$ & $12(1.4)$ & \\
\hline
\end{tabular}

Chi-square test

Table 5 Attitudes and compliance with hand hygiene $(n=1,282)$

\begin{tabular}{|c|c|c|c|c|c|c|}
\hline Item & Category & & Total & $\begin{array}{l}\text { Compliant } \\
n=436\end{array}$ & $\begin{array}{l}\text { Noncompliant } \\
n=846\end{array}$ & $P$-value \\
\hline \multirow{2}{*}{$\begin{array}{l}\text { I think I will take standard } \\
\text { precautions }\end{array}$} & Yes & \multirow[t]{2}{*}{$n(\%)$} & $1,026(83.0)$ & $361(85.7)$ & 665 (81.6) & \multirow[t]{2}{*}{0.065} \\
\hline & No & & $210(17.0)$ & $60(14.3)$ & $150(18.4)$ & \\
\hline \multirow{2}{*}{$\begin{array}{l}\text { I think hand washing is } \\
\text { effective in preventing } \\
\text { infection }\end{array}$} & Yes & \multirow[t]{2}{*}{$n(\%)$} & $1,252(97.9)$ & 429 (98.6) & $823(97.5)$ & \multirow[t]{2}{*}{0.191} \\
\hline & No & & $27(2.1)$ & $6(1.4)$ & $21(2.5)$ & \\
\hline \multirow{2}{*}{$\begin{array}{l}\text { I think infection can be } \\
\text { prevented by knowledge }\end{array}$} & Yes & \multirow[t]{2}{*}{$n(\%)$} & $1,177(92.2)$ & $413(95.2)$ & $764(90.7)$ & \multirow[t]{2}{*}{0.005} \\
\hline & No & & $99(7.8)$ & $21(4.8)$ & $78(9.3)$ & \\
\hline \multirow{2}{*}{$\begin{array}{l}\text { I think infection can be } \\
\text { prevented by proper behavior }\end{array}$} & Yes & \multirow[t]{2}{*}{$n(\%)$} & $1,163(91.4)$ & $406(94.2)$ & 757 (89.9) & \multirow[t]{2}{*}{0.010} \\
\hline & No & & $110(8.6)$ & $25(5.8)$ & $85(10.1)$ & \\
\hline \multirow{2}{*}{$\begin{array}{l}\text { I think I have knowledge of } \\
\text { infection }\end{array}$} & Yes & \multirow[t]{2}{*}{$n(\%)$} & $599(47.2)$ & $252(58.2)$ & 347 (41.5) & \multirow[t]{2}{*}{0.000} \\
\hline & No & & $671(52.8)$ & $181(41.8)$ & $490(58.5)$ & \\
\hline \multirow{2}{*}{$\begin{array}{l}\text { I think I can take appropriate } \\
\text { actions in poor health }\end{array}$} & Yes & \multirow[t]{2}{*}{$n(\%)$} & $661(52.9)$ & $277(65.3)$ & $384(46.5)$ & \multirow[t]{2}{*}{0.000} \\
\hline & No & & $589(47.1)$ & $147(34.7)$ & $442(53.5)$ & \\
\hline \multirow[t]{2}{*}{ I think I am busy at work } & Yes & \multirow[t]{2}{*}{$n(\%)$} & $1,159(91.3)$ & $402(92.8)$ & $757(90.4)$ & \multirow[t]{2}{*}{0.151} \\
\hline & No & & $111(8.7)$ & $31(7.2)$ & $80(9.6)$ & \\
\hline
\end{tabular}

Chi-square test

1.95). Other hand-hygiene-promoting factors identified by the analysis included "education" (OR 1.38), "I think I have knowledge of infection" (OR 1.86), and "I think I can take appropriate actions such as having a rest and seeing a doctor in poor health" (OR 1.66). Education and attitude showed significant correlations as hand-hygiene-promoting 
Table 6 Personal factors contributing to compliance with hand hygiene $(n=1,033)$

\begin{tabular}{llll}
\hline Factor & Conditions compared/factor & Odds ratio & Confidence interval \\
\hline Education & Adequate/inadequate & 1.38 & $1.04-1.83$ \\
I think I have knowledge of infection & Yes/no & 1.86 & $1.41-2.48$ \\
I think infection can be prevented by knowledge & Yes/no & 1.95 & $1.05-3.60$ \\
I think I can take appropriate actions in poor health & Yes/no & 1.66 & $1.26-2.18$ \\
\hline
\end{tabular}

Logistic regression analysis (step-down method)

factors, while basic characteristics and knowledge were not significant contributing factors (Table 6).

Facility-related factors contributing to compliance rate with hand hygiene

Multiple regression analysis (stepwise method) was performed using compliance rate with hand hygiene as dependent variable, and facility-related factors such as basic characteristics, infection control by the facility, and its environment as explanatory variables $(n=37)$.

"Implementation of hand-washing evaluation" (regression coefficient $\beta=0.42$ ) was strongly related with hand hygiene compliance rate. However, there was no significant related factor. The adjusted coefficient of determination was $R^{2}=0.15$.

\section{Discussion}

In this study, not many facilities responded, but the response rate of employees in the responding facilities was high. Therefore bias is small.

There were special nursing homes $(59.1 \%)$ and health service facilities $(40.8 \%)$ in Yamaguchi Prefecture, Japan, whose capacity was $71.6 \pm 20.2$ (mean \pm SD) and number of staff was $36.0 \pm 12.2$ (mean $\pm \mathrm{SD}$ ). We were able to collect data to represent the facilities in Yamaguchi Prefecture, Japan, because their type, capacity, and number of staff were not different from the subjects of this study.

The rate of compliance with hand washing and glove use was $34.0 \%$. Specifically, it was $30.5 \%$ in certified care workers, $33.7 \%$ in care workers (helpers), and $41.5 \%$ in nurses, with no significant differences between job types. Especially, the compliance rate in nurses was some $40 \%$, regardless of their learning about infections, infection control, standard precautions, and hand hygiene over the course of basic education. According to literature that summarized hand hygiene compliance rates in previous foreign studies, the compliance rates differed greatly, ranging from $5 \%$ to $81 \%$, and the mean rate was $40 \%$ [1]. The overall compliance rate in this study was $34.0 \%$, showing a trend similar to those in previous studies. The relatively low rate of compliance with hand hygiene has raised a problem at these facilities, and it is a major challenge to them to improve the compliance rate.

The study showed that hand hygiene was complied with by those who thought "infection can be prevented by knowledge," and/or "I have knowledge of infection." It is said that intentional behavior is associated with attitudes toward behavior and the subjective norm of behavior, and can be modified by approaching these factors [17]. Since the importance of attitudes was suggested in this study as well, the promotion of hand hygiene requires that care staff recognize the importance of hand hygiene and its effectiveness in preventing infection.

Education is essential in promoting compliance with hand hygiene. A previous study revealed that, as a result of intervention including education, the compliance rate improved from $56 \%$ before intervention to $83 \%$ after intervention, and then reduced to $76 \%$ during follow-up [18]. The hand hygiene compliance rate can improve through education, but this effect does not persist. As a correlation between those who had received education during the past year and their compliance with hand hygiene was observed in this study as well, it is necessary to continually encourage them to be aware of the importance of hand hygiene. While the importance of monitoring the compliance of care staff with hand hygiene is emphasized as a means to maintain and improve the compliance rate [19], evaluation of their hand-washing activities was found to be a factor increasing hand hygiene rate in this study as well. Hand washing can be evaluated by such methods as self-evaluation by a check sheet, observation, measurement of the amount of alcohol-based hand-rubs used, and evaluation using fluorescent lotion, which is applied to the hands and irradiated with ultraviolet rays from a black-light lamp after washing the hands to check for any remaining contamination. Black light provides a convenient, easy-to-use approach that allows self-check and facilitates self-awareness. Although only $26.2 \%$ of the facilities that responded to this survey applied the blacklight method, one idea to improve the hand hygiene compliance rate is to combine lectures with opportunities to self-evaluate hand washing by such means as a black-light in education for care staff. 
Preparing an environment readily conducive to hand washing brings about an improvement of hand hygiene, and, in fact there is a study demonstrating an improvement in the hand hygiene compliance rate by carrying a hand-rub in the pocket [20]. This study, however, did not show a correlation between carrying a hand-rub in the pocket and compliance with hand hygiene. As a hand-washing method for visibly unsoiled hands, the "use of an alcohol-based hand-rub," rather than "washing the hands with soap and water," is recommended [1]. However, the rate of correctly answering the question about this issue was only $31.2 \%$. This suggests the presence of care staff not knowing this CDC recommendation at facilities for the elderly, and the necessity to disseminate the CDC-recommended handwashing methods and alcohol-based hand-rubs among facilities.

Regarding the questions about infection routes, the correct answer rate was low for the question on MRSA, probably because the survey regarded droplet transmission as an incorrect answer to this question. Although MRSA is mainly transmitted via contact, there is still a possibility of it being transmitted by droplets. However, the survey requested the subjects to choose a more common infection route at facilities for the elderly when there was more than one possible route. For MRSA, these facilities primarily take preventive measures against contact transmission [14].

The subjects' knowledge of infection routes was scored and subjected to multivariate analysis, and it was found not to be a factor significantly correlated with compliance toward hand hygiene. While knowledge of infection routes was not a factor promoting hand hygiene, as described above, a positive attitude toward prevention was found to be a factor positively contributing to compliance with hand hygiene. As reported by Gruber et al. [21] and Ronk et al. [22], imparting knowledge does not always promote behavior. Since this study demonstrated the importance of training after employment, and confirmed greater value of attitudes than of personal knowledge, it was considered significant to provide care staff with education with content that could improve their attitudes. To achieve this, it is recommended to first explain to care staff the reasons why hand hygiene is necessary using literature, then promote their understanding of hand hygiene and behavior through a group discussion, and finally evaluate their compliance with hand hygiene and provide them with feedback. Evaluation of compliance with hand hygiene and its feedback are important as a "motivation" [23], and considered to be an effective method to promote attitudes toward hand hygiene.

This study explored personal and facility-related factors expected to contribute to compliance with hand hygiene. "Receipt of adequate education," "awareness of having knowledge of infection," "belief that infection can be prevented by knowledge," "ability to take appropriate actions in poor health," and "implementation of handwashing evaluation" were found to be factors improving compliance with hand hygiene. Therefore, it is effective to include these factors in measures for improvement of hand hygiene.

This study was based on a questionnaire survey, and in general self-evaluation tends to be better than the actual condition. Kakeya et al. [24] examined nurses' compliance with hand washing in 6 clinical scenes using both a questionnaire and observation, and reported compliance rates of $83.5 \%$ based on the questionnaire conducted among 39 nurses, and $68.9 \%$ based on the observation of 20 nurses. Since a questionnaire results in a higher compliance rate than observation, an accurate estimation of the hand hygiene compliance rate should be made based on observation. However, observation was not feasible in this study, which was based on a large-scale survey to collect as many data as possible to identify factors contributing to compliance with hand hygiene.

In addition, no causal relationship could be extracted from this study, which was cross-sectional. On the assumption that factors identified in this study are factors promoting compliance with hand hygiene, it is necessary to develop measures to improve the compliance rate, and conduct an interventional study.

In this study, the response rate to the questionnaire was relatively low, probably because it was conducted with the prior approval of the facility director. However, we could collect questionnaires from managers (75.0\%, 42/ 56) and care staff $(77.1 \%, 1,282 / 1,663)$. A response bias was considered, but we judged its influence to be small. Previous Japanese studies on compliance with hand hygiene mainly targeted one or several facilities, and no such studies have been conducted on a scale covering all facilities in a prefecture. Although its coverage was a single prefecture, this study was considered to be meaningful as it specifically targeted care staff at welfare facilities for the elderly, and explored not only personal factors but also facility-related factors contributing to compliance with health hygiene.

Acknowledgments We would like to thank people at the facilities for their cooperation in this study despite their busy schedules. This work was supported by KAKENHI (18791726).

\section{References}

1. Boyce JM, Pittet D. Guideline for hand hygiene in Health-Care Settings. Am J Infect Control. 2002;30:1-44.

2. Shimazaki Y. Hand hygiene. In: Infection preventive on facility for the elderly. Aichi: Nissokenz; 2005. pp. 16-21 (in Japanese).

3. Osuka Y. Factor influencing hand hygiene behavior of nurses. J Jpn Acad Nurs Sci. 2005;25:3-12. 
4. Inamatsu T. Facility for the elderly and infection control. In: The Japanese Association for Infectious Diseases, editor. Text of nosocomial infection control. Tokyo: Herusu Shuppan; 2000. pp. 176-83 (in Japanese).

5. Murata M. Infectious disease measures for a senior care. Health Care. 2005;47:170-5 (in Japanese).

6. Tsuji A. The report about method of infection control in a facility for the elderly. Ministry of Health, Labour and Welfare Special Science Project FY 2004. Tokyo; 2005. pp. 1-79 (in Japanese).

7. Eldeyly Health bureau, Ministry of Health, Labour and Welfare. Understanding for prevention of incidence and epidemic of infectious gastroenteritis in a facility for the elderly. Ministry of Health, Labour and Welfare. 2005. Notification No: 011001 (in Japanese).

8. Ministry of Health, Labour and Welfare Website. Virologic commentary about norovirus food poisoning or infectious disease of last year. 2007. (cited 2008 Oct 12) (in Japanese). Available at http://www.mhlw.go.jp/shingi/2007/08/d1/s0817-6e.pdf.

9. Infectious Disease Surveillance Center Website. Infection place of norovirus outbreaks. 2008 (in Japanese). [cited 2008 Oct 12]. Available at http://idsc.nih.go.jp/iasr/28/332/graph/t3323j.gif.

10. Barker J, Vipond IB, Bloomfield SF. Effects of cleaning and disinfection in reducing the spread of Norovirus contamination via environmental surfaces. J Hosp Infect. 2004;58:42-9.

11. Osuka Y. A factor to influence on hand hygiene. Jpn J Clin Nurs. 2007;33:352-6 (in Japanese).

12. Egami H. The report about method of support to prevention for infectious disease in a facility for the elderly. Ministry of Health, Labour and Welfare Community Health Promoting Project FY 2005. Yamaguchi; 2006. pp. 1-84 (in Japanese).

13. Takahashi I, Morita T, Yamazaki H, Murakami M, Ishikawa Y, Iijima S. The utilization and infectious control of the facilities for the elderly of patients or carriers. J Natl Inst Public Health. 2006;55:147-53.

14. Ministry of Health, Labour and Welfare. Infection control manual in a facility for the elderly. Ministry of Health, Labour and Welfare; 2005. pp. 1-57 (in Japanese).
15. Manda T. Basics of a nosocomial infection control. In: Nosocomial infection control for a nurse: Basics and practice from CDC guideline. Tokyo: Shorinsya; 2006. pp. 22-7 (in Japanese).

16. Tanaka F. Standard Precaution. In: Committees of ICP text editing, editor. ICP Text of ICP for an infection control practitioner. Osaka: Medicus Shuppan; 2006. pp. 152-8 (in Japanese).

17. O'Boyle CA, Henly SJ, Larson L. Understanding adherence to hand hygiene recommendations: the theory of planned behavior. Am J Infect Control. 2001;29:352-60.

18. Larson EL, Bryan JL, Adler LM, Blane C. A multifaceted approach to changing handwashing behavior. Am J Infect Control. 1997;25:3-10.

19. Pittet D, Hugonnet S, Harbarth S, Mourouga P, Sauvan V, Touveneau $S$, et al. Effectiveness of a hospital-wide programme to improve compliance with hand hygiene. Lancet. 2000;356:130712.

20. Pittet D, Simon A, Hugonnet S, Pessoa-Silva CL, Sauvan V, Perneger TV. Hand hygiene among physicians: performance, beliefs, and perceptions. Ann Intern Med. 2004;141:1-8.

21. Gruber M, Beavers FE, Johnson B, Brackett M, Lopez T, Feldman MJ, et al. The relationship between knowledge about acquired immunodeficiency syndrome and the implementation of universal precautions by registered nurses. Clin Nurse Spec. 1989;3:182-5.

22. Ronk LL, Girard NJ. Risk perception, universal precautions compliance. A descriptive study of nurses who circulate. AORN J. 1994;59:253-66.

23. Ichiki K. Point of making for hand hygiene manual. Jpn J Infect Control. 2008;17:434-9 (in Japanese).

24. Kakeya M, Senda Y. Evaluation of infection control education to advanced beginner nurses in a hospital. Environ Infect. 2004;19:409-14. 